\title{
Effect of water quality on waterbugs (Hemiptera: Gerromorpha \& Nepomorpha) in Flanders (Belgium): results from a large-scale field survey
}

\author{
Koen Lock $^{1 *}$, Tim Adriaens ${ }^{2}$, Frank Van De Meutter ${ }^{2}$ and Peter Goethals ${ }^{3}$ \\ 1 eCOAST Marine Research, Esplanadestraat 1, 8400 Oostende, Belgium \\ 2 Research Institute for Nature and Forest, Kliniekstraat 25, 1070 Brussels, Belgium \\ 3 Laboratory of Environmental Toxicology and Aquatic Ecology, Ghent University, J. Plateaustraat 22, 9000 Ghent, Belgium
}

Received 26 January 2013; Accepted 25 April 2013

\begin{abstract}
Macroinvertebrates have been collected in Flanders since 1989 by the Flemish Environment Agency to assess ecological water quality. During the present study, the collected waterbugs were identified to species level. In total, more than 90000 waterbugs were identified, belonging to 45 species. Two of these are recent additions to Flemish fauna: Sigara iactans was found to be a common species in 1989, the first year of monitoring, which is earlier than the first records reported so far, whereas Cymatia rogenhoferi remains a very rare species. Five different communities could be recognized: (1) species occurring in alkaline waters with a high $\mathrm{pH}$, (2) species occurring in colder waters that can tolerate slightly brackish and nutrient rich water, (3) species from running waters, (4) species from acidic waters and (5) ubiquist species that occurred in all types of water. Owing to the general improvement of chemical water quality during the last decade, most species increased, however, three pollution tolerant species declined significantly: Callicorixa praeusta, Corixa punctata and Sigara striata.
\end{abstract}

Key words: ecological water quality / Flanders / geographical distribution / monitoring / waterbugs

\section{Introduction}

Owing to habitat destruction and degradation, pollution, flow modification and invasion by alien species, fresh waters are experiencing decline in biodiversity far greater than those in the most affected terrestrial ecosystems (Sala et al., 2000). Although some industrialized countries have made considerable progress in reducing water pollution from domestic and industrial point sources, threats from excessive nutrient enrichment are still growing (Smith, 2003) and the number of alien species keeps increasing (Messiaen et al., 2010). Also in Flanders, river management has until present been mainly conducted at the river basin level by installing wastewater treatment plants and imposing standards for effluent concentrations. Although these measures have already resulted in a significant improvement of chemical and ecological water quality since the 1980s (VMM, 2010), most Flemish water bodies still lack good ecological status which the European Union Water Framework Directive (WFD) requires by 2015 (European Council, 2000).

\footnotetext{
*Corresponding author: Koen_Lock@hotmail.com
}

Nature conservation policy in Belgium is the responsibility of regional governments (Flanders, Brussels and Wallonia) and a regional scale is thus appropriate to perform faunistic studies or to develop red lists. Surface waters in Flanders, the northern part of Belgium, suffer from multiple threats. Flanders has a very high population density of 456 citizens. $\mathrm{km}^{-2}$, about $88 \%$ of the households are connected to a sewage system, but only $70.3 \%$ is actually treated (VMM, 2009). Flanders is also heavily industrialized and exhibits (mainly intensive) agriculture on $53 \%$ of the land (VMM, 2009). In addition, structural integrity of surface waters is threatened by thousands of weirs that have been built for flood control, hundreds of kilometres of artificial banks that have been installed and because the majority of the river channels have been straightened.

In order to assess ecological water quality, the use of biotic indicators (macrobenthic fauna, fish fauna, phytoplankton, phytobenthos and macrophytes) is required by the WFD. In order to meet the requirements of the WFD, Multimetric Macroinvertebrate Index Flanders (MMIF; Gabriels et al., 2010) was recently developed. This is a type-specific multimetric index consisting of five equally 
weighted metrics such as taxa richness, the number of EPT-taxa (Ephemeroptera, Plecoptera and Trichoptera), the number of other sensitive taxa, the Shannon-Wiener diversity index and mean tolerance score.

The prevalence of most common macroinvertebrate taxa in Flanders increased over the last two decades (Lock et al., unpublished data), which could be linked to general improvement of chemical water quality (VMM, 2010). However, several genera of waterbugs were remarkable exceptions to this rule. Therefore, this group was studied in more detail during the present study by identifying all specimens captured by the Flemish Environment Agency to species level and by linking their presence to measured environmental parameters.

\section{Materials and methods}

In the context of water quality monitoring by the Flemish Environment Agency, macroinvertebrates have been sampled at several thousand sampling points since 1989. Since water quality monitoring has focused especially on running waters, stagnant waters were underrepresented (Table 1). During monitoring, macroinvertebrates were sampled using a standard handnet, as described by Gabriels et al. (2010): a stretch of 10-20 m was sampled for approximately 5 min by kick sampling.

At each sampling event, conductivity, dissolved oxygen and $\mathrm{pH}$ were measured in the field. Other chemical variables (content of ammonium, nitrite, nitrate, Kjeldahl nitrogen, orthophosphate, total phosphorus, chemical oxygen demand and biological oxygen demand) were retrieved from monitoring data of chemical water quality of Flemish surface waters, which was also performed by the Flemish Environment Agency. As chemical monitoring, which was usually performed on a monthly basis, was not performed simultaneously with the macroinvertebrate sampling, measurements from the last date before macroinvertebrate sampling were used. The slope of a watercourse was determined based on the difference in height between two points $1000 \mathrm{~m}$ apart using GIS-software applied on the Flemish Hydrographic Atlas (AGIV, 2006). These data were also used to determine the sinuosity on a stretch of $100 \mathrm{~m}$. River morphology was evaluated based on photographs of the sampling sites: pool-riffle pattern and meandering were both assigned a value from 0 (absent) to 5 (well developed) and summed, which yielded a score from 0 to 10 .

As the highest point in the study area had an altitude of only $288 \mathrm{~m}$ asl, the whole region could be considered as lowland. A map of Flanders with indication of different ecoregions is presented in Figure 1. All sampled waterbugs were identified to species level by using the identification key given by Tempelman and Van Haaren (2009).

Box and whisker plots (showing median, 25-75 percentiles and 5-95 percentiles), were made for the parameters measured during sampling. A direct gradient analysis was applied to determine, which environmental parameters might be responsible for differences in species composition, since environmental variables were explicitly incorporated in the analysis. To test whether a linear or unimodal method was needed, detrended correspondence analysis (DCA) was performed. Since the length of gradient (LoG) was greater than four, a unimodal method was needed and therefore, canonical correspondence analysis (CCA) option from program package CANOCO (Ter Braak, 1988) was applied. Only the seven most important parameters were plotted and only species that were captured on at least ten occasions were included in the analysis. A $\log$-transformation $(\log (x+1))$ was applied prior to the CCA to normalize the data.

\section{Results}

During the present study, more than 90000 waterbugs have been identified, representing almost 9000 records. In total, 45 different species were encountered (Table 1). Most species tolerated moderate conductivities, only a few species from running waters (i.e., Aphelocheirus aestivalis) and acidic waters (i.e., Hesperocorixa castanea and Notonecta obliqua) were only found at low conductivities (Fig. 2A). On the other hand, some species could be found in waters with a very high conductivity. These species, such as Corixa affinis and Paracorixa concinna, tolerate brackish water conditions (Fig. 2A). Only A. aestivalis was restricted to waters with high oxygen content, other species were also found in waters with moderate oxygen concentrations (Fig. 2B). Most species occurred over a wide range of $\mathrm{pH}$ values, however, only a few (i.e., $H$. castanea and $N$. obliqua) were found in acidic waters (Fig. 2C). A. aestivalis only occurred at low nutrient concentrations, while most species tolerated relatively high concentrations (Figs 2D-F).

In the CCA, the first axis (eigenvalue of 0.093) coincided mainly with high levels of ammonium $(R=0.19)$ and orthophosphate $(R=0.22)$ and low levels of oxygen $(R=-0.13)$, indicating eutrophication is an important factor affecting species composition (Fig. 3). The second axis (eigenvalue 0.076) coincided mainly with high nitrate concentrations $(0.16)$ and low values of $\mathrm{pH}(R=-0.24)$ and conductivity $(R=-0.22)$ (Fig. 3$)$. Within the species scatter, five groups of species could be
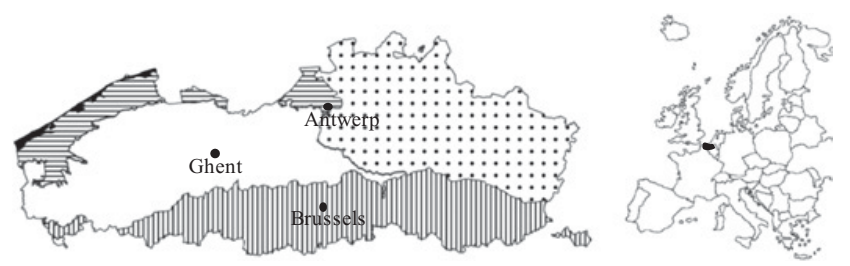

Fig. 1. Map of Flanders with indication of different ecoregions: dune area (black), polder area (horizontal stripes), sandy region (white), Campine region (dots) and loamy region (vertical stripes); the location of Flanders has been marked on the map of Europe. 


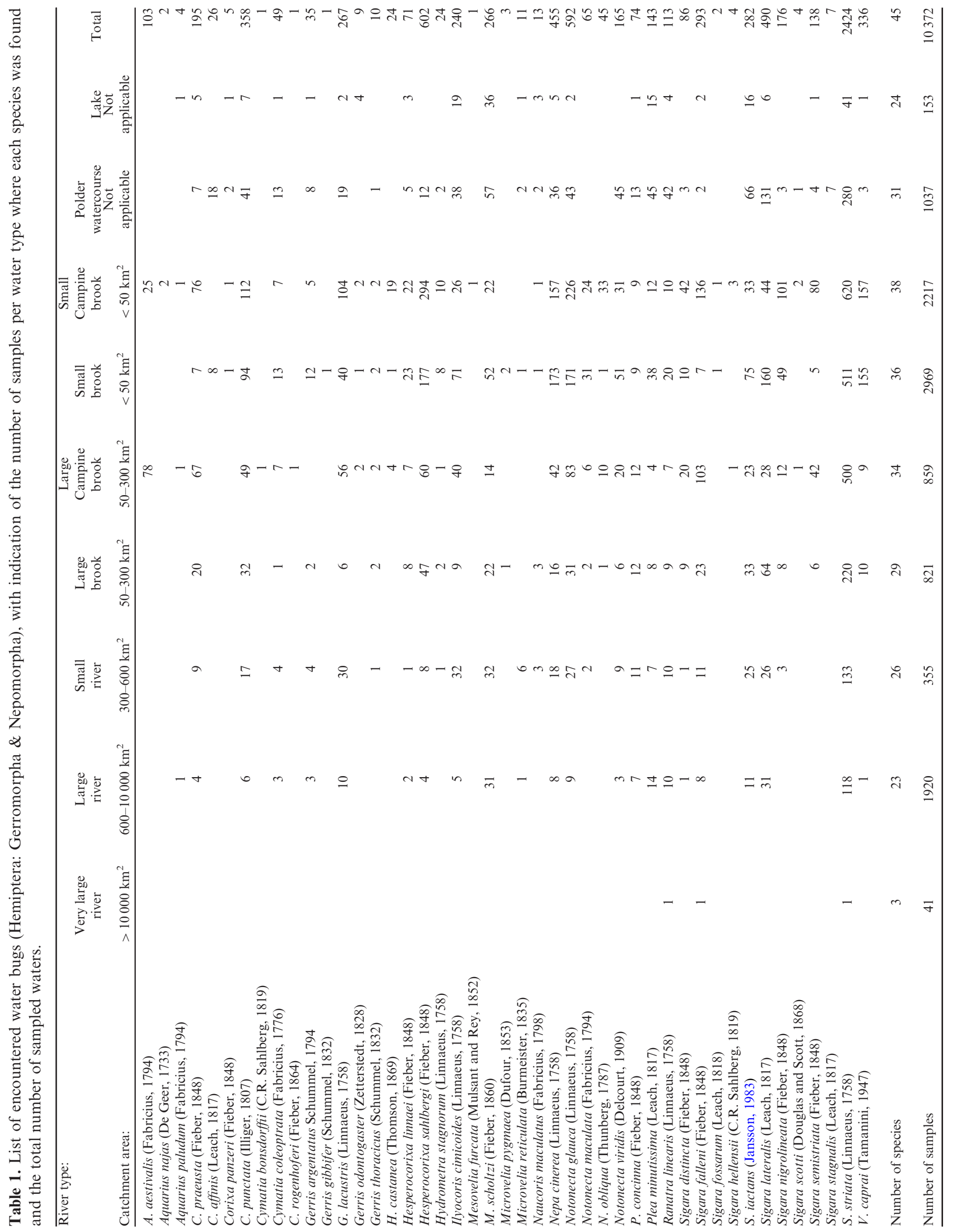



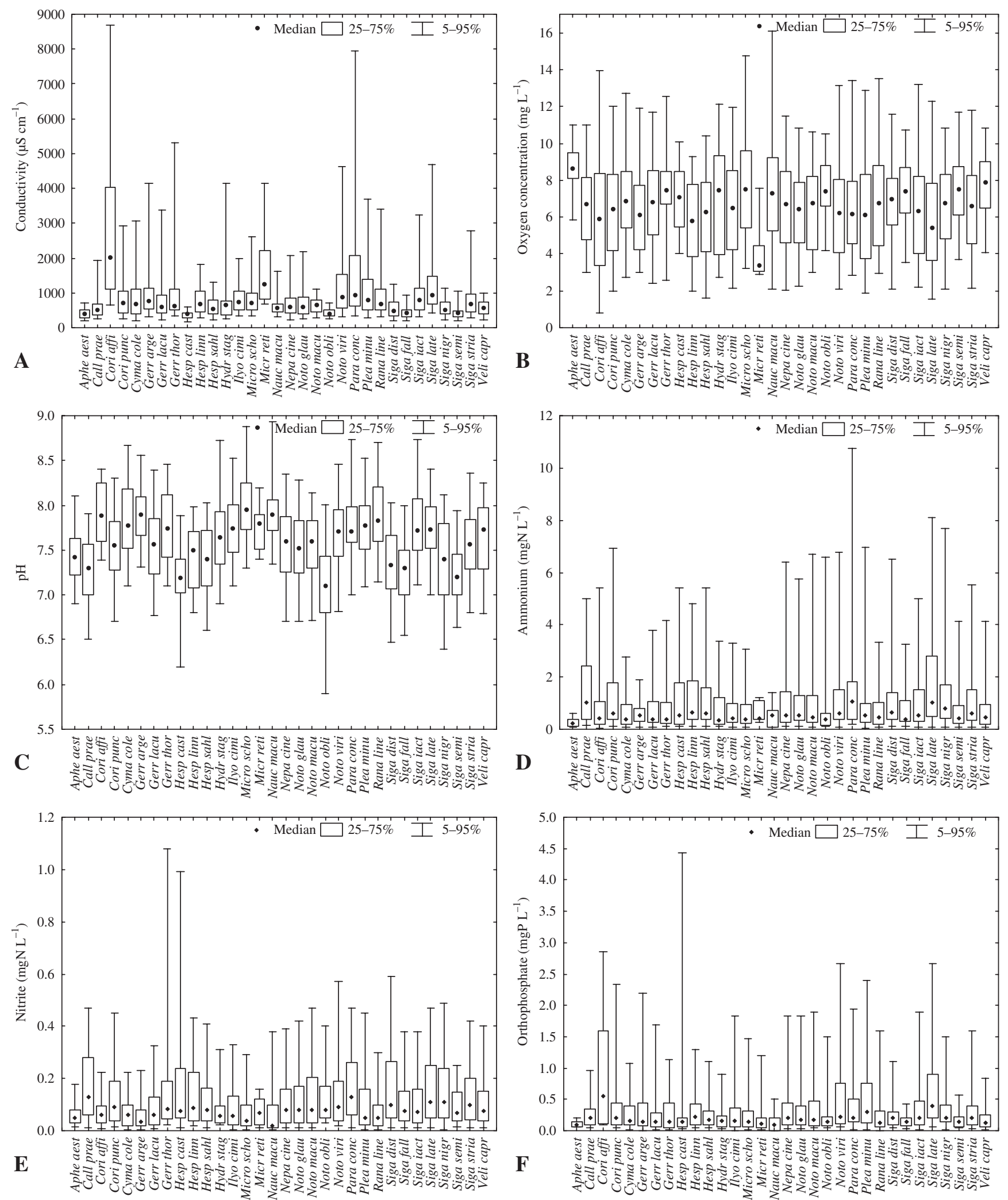

Fig. 2. Box \& Whisker plots of oxygen concentration (A), conductivity (B), pH (C), ammonium content (D), nitrite content (E) and orthophosphate content (F) for the 32 most abundant waterbugs.

recognized. In the lower left of the biplot (dashed ellipse), species characteristic for alkaline waters with a high $\mathrm{pH}$ is plotted. Species that were mainly found in the colder ecoregion with its clay soils and waters with high conductivity and high orthophosphate concentration were plotted in the lower right of the biplot (dotted ellipse). 


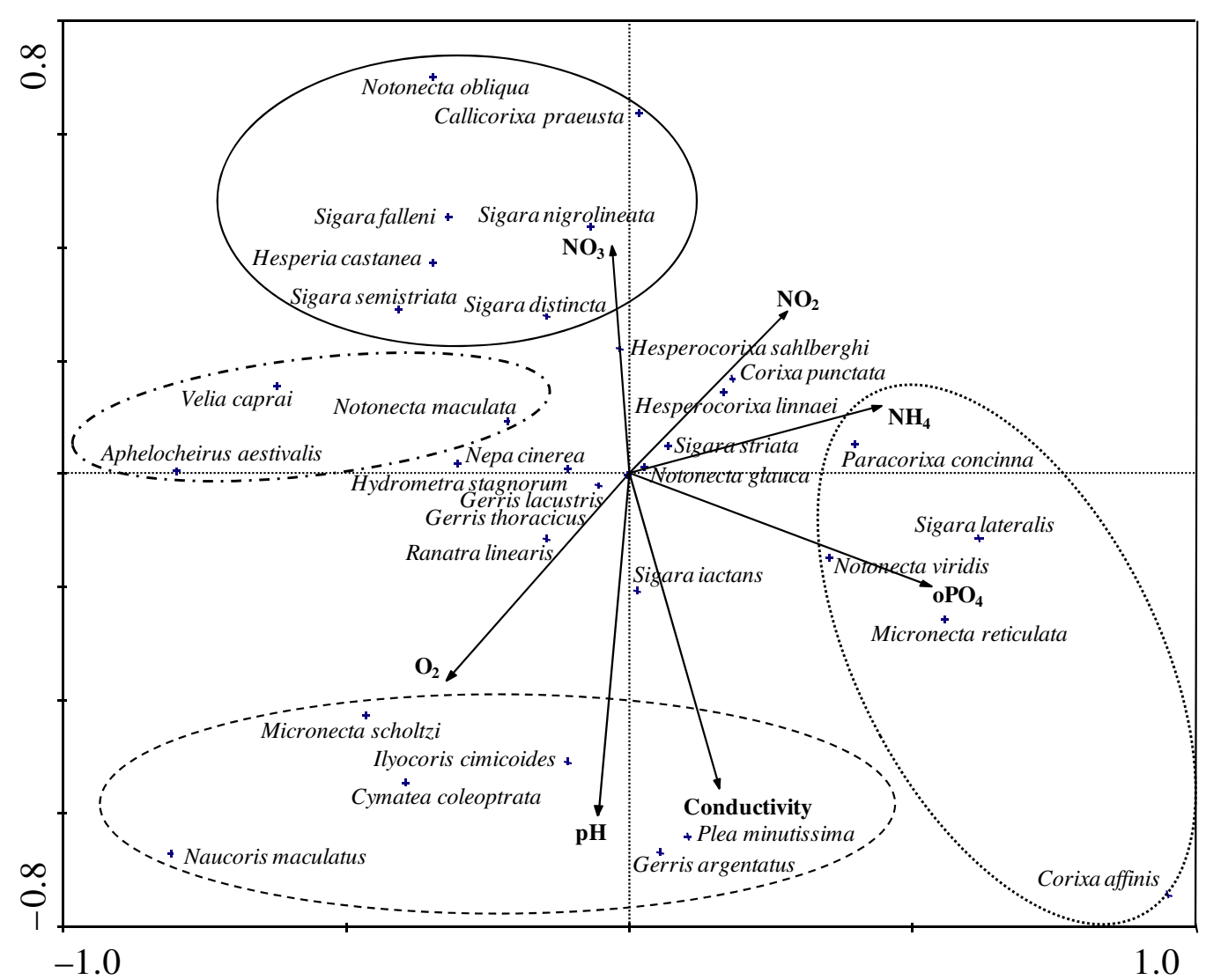

Fig. 3. CCA biplot of species scores and the seven most important environmental variables. Only species that were captured on at least ten occasions were taken into account.

In the upper left of the biplot, species are plotted that occurred in acidic waters (full ellipse), which are characterized by low values of $\mathrm{pH}$ and conductivity and somewhat more to the centre of the biplot, species are plotted that are characteristic for running waters (dashed \& dotted ellipse), which are characterized by higher values of oxygen and $\mathrm{pH}$. The remaining species, which are plotted in the centre of the biplot, are ubiquist species that occurred in all types of waters.

Within Flanders, many of the measured environmental variables display important spatial gradients, which may be reflected in the distribution of waterbugs. For each of these groups, some examples of the distribution area are presented in Figure 4 (distribution maps for all species are available in the online material).

Since the start of monitoring, several genera significantly declined (Spearman, $P<0.05$ ): Sigara, Corixa and Callicorixa (Fig. 5A). This decrease could mainly be attributed to the declining numbers of the species Sigara striata and Corixa punctata, while Callicorixa is only represented by $C$. praeusta in Flanders. On the other hand, there were also some other genera that significantly increased (Spearman, $P<0.05$ ): Gerris, Micronecta and Velia (Fig. 5B). The increase of Gerris could mainly be attributed to Gerris lacustris, while Micronecta scholtzi and Velia caprai are the only species of the latter two genera that were found during the present study.

\section{Discussion}

During the present study, 45 species were encountered of the 60 species of waterbugs that have been reported for Flanders. Six species are probably regionally extinct in Flanders: Hesperocorixa moesta, Notonecta lutea, Notonecta reuteri, Sigara longipalis, Sigara selecta and Velia saulii. The remaining species that were not recorded here are mostly species that are restricted to stagnant waters such as fens, which were underrepresented in the present study (Table 1). In addition, most of these species are rare and figure on the red list of the Gerromorpha and Nepomorpha of Flanders (Lock et al., in press).

Two of the encountered species are recent additions to Belgian fauna that are still extending their distribution area: Sigara iactans and Cymatia rogenhoferi. S. iactans was only recently recognized as a separate species (Jansson, 1983). The species had previously been recorded from Belgium since 1991 (Vercauteren, 1997). However, during the present study, it was found that the species was already widespread in 1989, the first year of water quality monitoring by the Flemish Environment Agency. In the Netherlands, the species was already widespread in the beginning of the eighties and one specimen had already been caught in 1953 (Aukema et al., 2002). Therefore, historical collections of the Royal Belgian Institute of 

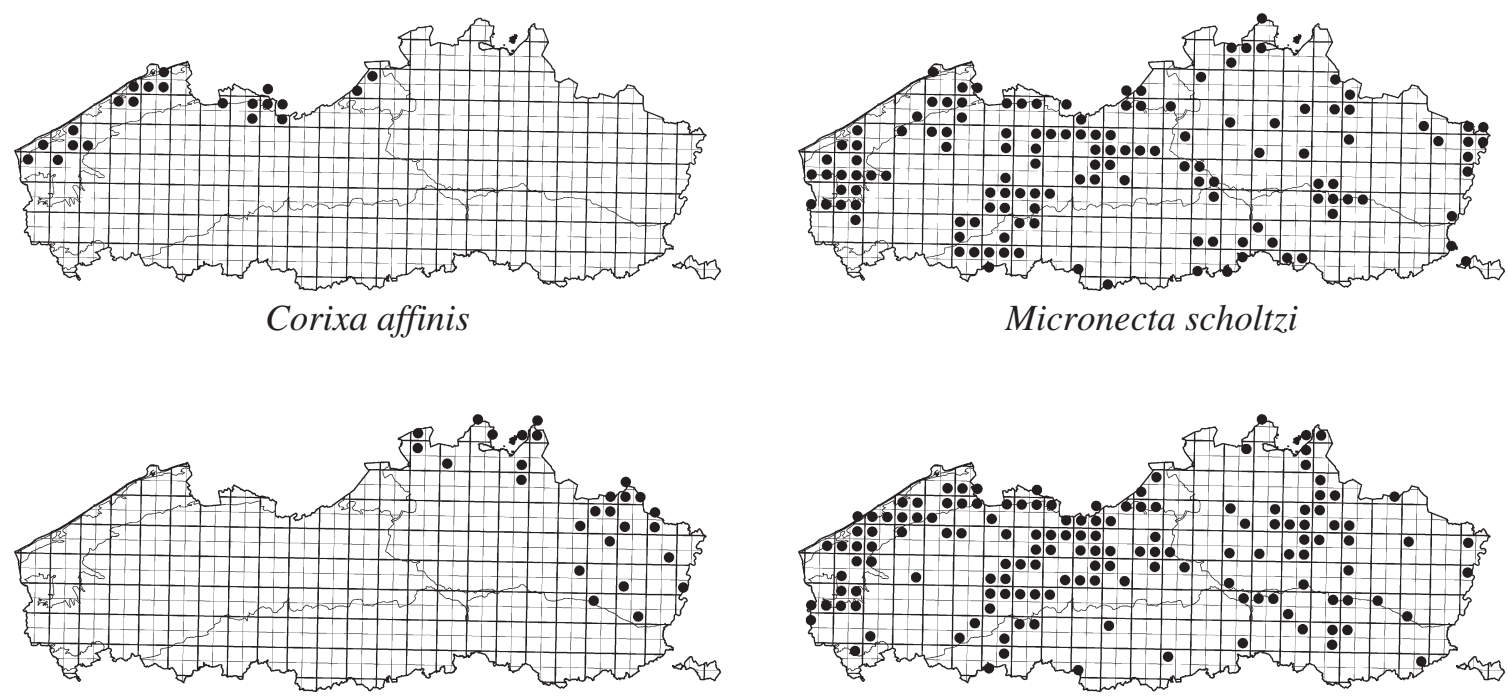

Notonecta obliqua

Sigara iactans

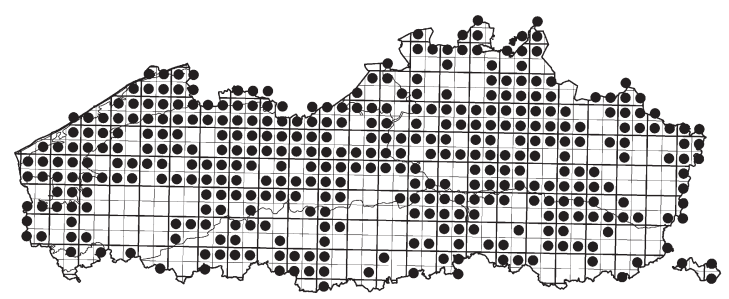

Sigara striata

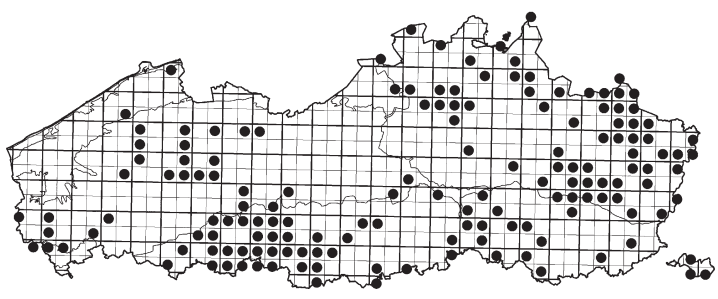

Velia caprai

Fig. 4. Distribution of C. affinis, M. scholtzi, N. obliqua, S. iactans, S. striata and V. caprai in Flanders, with indication of the ecoregions and a grid of $5 \times 5 \mathrm{~km}$ UTM-squares.

Natural Sciences were checked, but no S. iactans were found. S. iactans is now a common species in Flanders (Fig. 4) and seems to continue colonizing Western-Europe: France since 1995 (Elder and Chéreau, 2003) and the UK since 2004 (Nau and Brooke, 2006). C. rogenhoferi was found in the river Grote Nete in 2006. This species has been observed occasionally in Belgium since 2001 (Stoffelen et al., unpublished data). This phenomenon is acting on a Western-European scale: first observations: Netherlands, 1991; France, 1998, UK, 2005 (Aukema et al., 2002; Elder, 2002; Nau and Brooke, 2006). However, this species remains rare and it is usually only present temporarily and rarely in high numbers.

The MMIF (Gabriels et al., 2010) is used to assess ecological water quality in Flanders. In the MMIF, all taxa were assigned a tolerance score ranging from 1 (indicator of very poor ecological water quality) to 10 (indicator of very good ecological water quality). Aphelocheirus received the highest tolerance score of all waterbugs (8), Microvelia and Velia were also assigned a high score (7), while all other species were rated as 5 or 6 . Also, in the present study, Aphelocheirus was clearly the most sensitive waterbug and Velia was indeed quite sensitive. However, Microvelia tolerated high conductivities and low oxygen concentrations, which does not support its high tolerance score, but since this genus is so rare, this hardly ever affected the outcome of the MMIF. Most waterbugs have a moderate tolerance score, which explains why not much variation was observed in the concentrations of oxygen and nutrients at which different species were sampled. It can be concluded that there was good agreement between the tolerance scores used by Gabriels et al. (2010) and the results obtained during the present study. However, it should be noted that in both studies, sensitivity was mainly related, either directly or indirectly, to dissolved oxygen concentration, whereas other potentially important parameters, such as habitat requirements or fish predation, were not taken into account.

When waterbugs are compared with stoneflies, it is obvious that stoneflies are much more sensitive to low oxygen concentrations, high conductivities and high nutrient concentrations (Lock and Goethals, 2008). Also most mayfly species (Lock and Goethals, 2011) and caddisfly species (Lock and Goethals, 2012) are more sensitive than waterbugs. This justifies why most stoneflies, mayflies and caddisflies were assigned higher tolerance scores than waterbugs (Gabriels et al., 2010). Lower sensitivity of waterbugs can be explained by the fact that all adults, with the exception of $A$. aestivalis, are not dependent on oxygen dissolved in water since they collect air at the water surface. This is also the reason why 

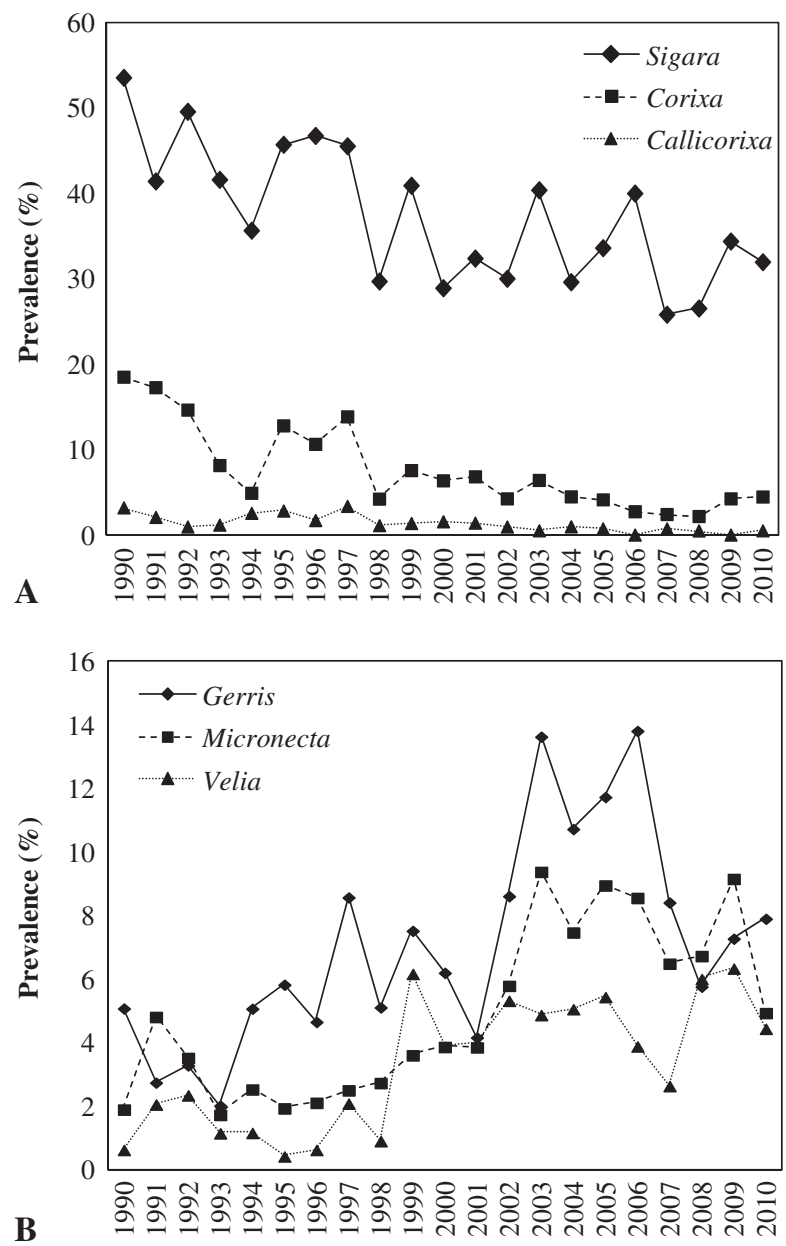

Fig. 5. Evolution of the prevalence of some significantly increasing (A) and some significantly decreasing (B) genera from 1990 to 2010 .

waterbugs are usually absent from deep waters such as canals.

Owing to the general improvement of chemical and ecological water quality in Flanders, the prevalence of many aquatic macroinvertebrates has increased since the 1990s (Lock et al., unpublished data). Some examples within the Hemiptera are G. lacustris, M. scholtzi and V. caprai (Fig. 5B). For G. lacustris and V. caprai, which both depend on surface tension of water, decreased use of persistent detergents may also have promoted their comeback. However, some Corixidae do not seem to follow this general positive trend. For example, Callicorixa praeusta, $C$. punctata and S. striata significantly declined over the study period. These species have a large tolerance to low oxygen levels in water, since they breathe aerial oxygen, which they collect at the water surface. This makes it unlikely that they are directly affected by changes in dissolved oxygen in Flemish surface waters. A possible indirect mechanism at play may be increase of fish densities due to improvement of water quality. Corixids indeed are sensitive to predation by fish species, which may differ between species (Oscarson, 1987). Another possibility is that the amelioration of water quality led to a reduction of important food sources of corixids such as periphyton, chironomids and oligochaetes (Popham et al., 1984), which are almost abundant under high nutrient conditions. The improvement of water quality might thus indirectly have reduced prevalence of these waterbugs.

Acknowledgements. We would like to acknowledge the Flemish Environment Agency for the opportunity to study their collections. For help during study of the collections, we thank Rose Sablon and Thierry Backeljau from the Royal Belgian Institute of Natural Sciences. Koen Lock was supported by a Postdoctoral fellowship from the Fund for Scientific Research during identification of the waterbugs (FWO-Vlaanderen, Belgium).

\section{References}

AGIV, 2006. Flemish Hydrographic Atlas. Agentschap voor Geografische Informatie Vlaanderen, Ghent, available online at: http://geo-vlaanderen.agiv.be/geo-vlaanderen/vha

Aukema B., Cuppen J.G.M., Nieser N. and Tempelman D., 2002. Verspreidingsatlas Nederlandse Wantsen, European Invertebrate Survey, Leiden.

Elder J.-F., 2002. Capture récente en France de Cymatia rogenhoferi (Fieber, 1864) et description des stades juvéniles (Heteroptera, Corixidae). Bull. Soc. Entomol. Fr., 107, 43-49.

Elder J.-F. and Chéreau L., 2003. Une nouvelle espèce d'Hydrocorise pour la faune de France: Sigara (Subsigara) iactans Jansson, 1983. Bull. Soc. Entomol. Fr., 108, 405-407.

European Council, 2000. Directive 2000/60/EC of the European Parliament and of the Council of 23 October 2000 establishing a framework for Community action in the field of water policy. Official Journal of the European Communities, L327, Brussels, 72 p.

Gabriels W., Lock K., De Pauw N. and Goethals P.L.M., 2010. Multimetric Macroinvertebrate Index Flanders (MMIF) for biological assessment of rivers and lakes in Flanders (Belgium). Limnologica, 40, 199-207.

Jansson A., 1983. Three new palaearctic species of Sigara (Subsigara) (Heteroptera, Corixidae). Ann. Entomol. Fennici, 49, 65-70.

Lock K. and Goethals P.L.M., 2008. Distribution and ecology of the stoneflies (Plecoptera) of Flanders (Belgium). Ann. Limnol. - Int. J. Limnol., 44, 203-213.

Lock K. and Goethals P.L.M., 2011. Distribution and ecology of the mayflies (Ephemeroptera) of Flanders (Belgium). Ann. Limnol. - Int. J. Limnol., 47, 159-165.

Lock K. and Goethals P.L.M., 2012. Distribution and ecology of the caddisflies (Trichoptera) of Flanders (Belgium). Ann. Limnol. - Int. J. Limnol., 48, 31-37.

Lock K., Stoffelen E., Vercauteren T., Bosmans R. and Adriaens $\mathrm{T}$., in press. Updated red list of the water bugs (Hemiptera: Gerromorpha \& Nepomorpha) in Flanders (Belgium). Bull. Soc. R. Belg. Entomol. 149

Messiaen M., Lock K., Gabriels W., Vercauteren T., Wouters K., Boets P. and Goethals P.L.M., 2010. Alien macrocrustaceans in freshwater ecosystems in the eastern part of Flanders (Belgium). Belg. J. Zool., 140, 30-39.

Nau B.X. and Brooke S.E., 2006. Two waterbugs new to Britain, Cymatia rogenhoferi Fieber and Sigara iactans Jansson 
(Hem., Corixidae), with comments on migration. Entomol. Mon. Mag., 142, 229-234.

Oscarson H.G., 1987. Habitat segregation in a water boatman (Corixidae) assemblage - the role of predation. Oikos, 49, 133-140.

Popham E.J., Bryant M.T. and Savage A.A., 1984. The role of front legs of British corixid bugs in feeding and mating. J. Nat. Hist., 18, 445-464.

Sala O.E., Chapin F.S., Armesto J.J., Berlow R., Bloomfield J., Dirzo R., Huber-Sanwald E., Huenneke L.F., Jackson R.B., Kinzig A., Leemans R., Lodge D., Mooney H.A., Oesterheld M., Poff N.L., Sykes M.T., Walker B.H. and Wall D.H., 2000. Global biodiversity scenarios for the year 2100 . Science, 287, 1770-1774.

Smith V.H., 2003. Eutrophication of freshwater and coastal marine ecosystems - a global problem. Environ. Sci. Pollut. Res., 10, 126-139.
Tempelman D. and Van Haaren T., 2009. Water- en oppervlaktewantsen van Nederland, Jeugdbondsuitgeverij, Utrecht.

Ter Braak C.J.F., 1988. CANOCO - a FORTRAN program for canonical community ordination by (partial) (canonical) correspondence analysis, principal components analysis and redundancy analysis (version 2.1). Agricultural Mat. Group, Ministry of Agriculture and Fisheries (Netherlands), Wageningen, $95 \mathrm{p}$.

Vercauteren T., 1997. Sigara (Subsigara) iactans, een nieuwe soort voor België (Heteroptera: Corixidae). Phegea, 25, 97-105.

VMM, 2009. MIR-T 2008 Indicator report [in Dutch]. Van Steertegem M. (red.), Environmental Report Flanders, Flemish Environment Agency, Aalst, 164.

VMM, 2010. Annual Report Water 2009 [in Dutch], Flemish Environment Agency, Available online at: http:// www.vmm.be/pub/jaarrapport-water-2009. 